\title{
Consequences of mitral valve prolapse on chordal tension: Ex vivo and in vivo studies in large animal models
}

\author{
Mathieu Granier, MD, MSc, ${ }^{\mathrm{a}, \mathrm{b}, \mathrm{c}}$ Morten O. Jensen, PhD, ${ }^{\mathrm{d}, \mathrm{e}}$ Jesper L. Honge, MD, ${ }^{\mathrm{e}}$ Alain Bel, MD, ${ }^{\mathrm{a}, \mathrm{b}, \mathrm{c}, \mathrm{f}}$ \\ Philippe Menasché, MD, PhD, ${ }^{\mathrm{a}, \mathrm{b}, \mathrm{c}, \mathrm{f}}$ Sten L. Nielsen, MD, PhD, DMSc, ${ }^{\mathrm{e}}$ Alain Carpentier, MD, PhD, ${ }^{\mathrm{a}, \mathrm{b}, \mathrm{c}, \mathrm{f}}$ \\ Robert A. Levine, MD, ${ }^{\mathrm{g}}$ and Albert A. Hagège, MD, PhD, ${ }^{\text {b,c,h }}$ Paris, France, Aarhus, Denmark, and Boston, \\ Mass
}

Mitral valve prolapse (MVP) often leads to important mitral regurgitation (MR), particularly after chordal rupture, but its mechanisms remain elusive because of the lack of an appropriate model. This study aimed to create such a model by implanting a pericardial patch within the anterior mitral leaflet (AML) in large animals (sheep, pig), allowing acute primary biomechanical consequences of MVP on chordae tendineae force (CTF) to be evaluated.

\section{CLINICAL SUMMARY}

\section{Surgical Procedure}

Ex vivo studies in 3 pig and 6 sheep hearts showed that the use of a large autologous oval pericardial patch (area at least equal to and not more than twice that of the AML) sutured along the base of the AML (after an incision along the annulus) was the most appropriate procedure to create MVP without MR, as demonstrated by echography performed during heart immersion in a saline solution while pressurized water was injected into the left ventricle (LV) through the aortic root (Figure 1).

\footnotetext{
From the Laboratory of Biosurgical Research, ${ }^{\text {a }}$ Foundation Alain Carpentier, Paris, France; INSERM U 633, ${ }^{\text {b }}$ Paris Cardiovascular Research Center, Paris, France; University Paris Descartes, ${ }^{c}$ Sorbonne Paris Cité, Paris, France; Department of Biomedical Engineering, ${ }^{\mathrm{d}}$ Engineering College of Aarhus, Denmark; Department of Cardiothoracic and Vascular Surgery, ${ }^{\mathrm{e}}$ Aarhus University Hospital, Skejby, Aarhus, Denmark; Assistance Publique-Hôpitaux de Paris, ${ }^{\mathrm{f}}$ Hôpital Européen Georges Pompidou, Department of Cardiovascular Surgery, Paris, France; Cardiac Ultrasound Laboratory, ${ }^{\mathrm{g}}$ Harvard Medical School, Massachusetts General Hospital, Boston, Mass; and Assistance Publique-Hôpitaux de Paris, ${ }^{\text {h }}$ Hôpital Européen Georges Pompidou, Department of Cardiology, Paris, France

This research project was funded by Grant 07CVD04 (M.G., M.O.J., J.L.H., S.L.N., A.C., R.A.L., A.A.H.) from the Leducq Foundation, Paris, France, for the Leducq MITRAL Transatlantic Network. M.G. was also funded by a grant from the French Society of Cardiology and the French Federation of Cardiology. J.L.H. and M.O.J. were funded by the Danish Heart Foundation Grant 07-4-B248-A1380-22362, the Central Denmark Region Health Science Research Fund, and the A.P. Møller Foundation for the Advancement of Medical Science, Snedkermester Sophus Jacobsen og hustru Astrid Jacobsens Fond, Hørslev Fonden. R.A.L.'s participation was supported by National Heart, Lung, and Blood Institute Grant K24 HL67434.

Disclosures: Authors have nothing to disclose with regard to commercial support. M.G. and M.O.J. equally contributed to the work.

Received for publication June 1, 2011; revisions received Aug 15, 2011; accepted for publication Aug 25, 2011; available ahead of print Sept 28, 2011.

Address for reprints: Albert A. Hagège, MD, PhD, Department of Cardiology, Hôpital Européen Georges Pompidou, 20 Rue Leblanc, 75015 Paris, France (E-mail: albert. hagege@egp.aphp.fr).

J Thorac Cardiovasc Surg 2011;142:1585-7

0022-5223/\$36.00

Copyright (C) 2011 by The American Association for Thoracic Surgery

doi:10.1016/j.jtcvs.2011.08.035
}

\section{Echocardiographic Data}

In vivo, 6 adult sheep $(45 \mathrm{~kg})$ underwent epicardial echocardiography (Sequoia 516, Acuson, Mountain View, Calif) before and after patch insertion to generate the following measurements: LV ejection fraction (biplane Simpson's rule), maximal length of the AML (apical 3-chamber view), maximal systolic annulus diameter, and maximal prolapse extent into the left atrium beyond a line connecting the annular hinge points. Color Doppler MR greater than $1+$ was considered significant.

\section{Chordae Tendineae Force Measurements}

CTFs were measured before and after patch insertion ex vivo in 11 excised pig hearts at 3 specified levels of $\mathrm{LV}$ pressure $(50,75$, and $100 \mathrm{~mm} \mathrm{Hg}$ ) and in vivo in 4 Danish Landrace/Yorkshire pigs $(80 \mathrm{~kg})$. Dedicated miniature $\mathrm{C}$-shaped strain gauge force transducers ${ }^{1}$ were sutured onto the middle part of each of the 2 main strut (secondary) chordae of the AML. LV pressures were recorded using Millar catheters (Millar Instruments Inc, Houston, Tex). Transducers were connected to a module rack (NI cDAQ 9172, National Instruments Corp, Austin, Tex) with 2 input modules (NI 9215, NI 9237). Recordings were performed with virtual instrumentation using an in-house build dataacquisition program (LabVIEW 8.6; National Instruments).

\section{Statistics}

Results are expressed as mean \pm standard deviation. We compared (SAS 9.2) tension measurements using a nonparametric Friedman's test, variations of mean tensions using a Wilcoxon's test, changes in CTFs and LV pressures using a nonparametric Wilcoxon's test, and ultrasonic measurements using a paired Wilcoxon's test.

\section{RESULTS}

\section{Mitral Valve Prolapse Pattern}

In vivo, patch insertion resulted in a marked bulge of the AML reaching $4.9 \pm 2.4 \mathrm{~mm}$ with a parallel increase of AML length $(16.6 \pm 1.5 \mathrm{~mm}$ to $27.3 \pm 4.6 \mathrm{~mm}, P=.03)$ without significant MR (Figure 1); LV volumes, ejection fractions, and annulus diameters remained unchanged.

\section{Ex Vivo Chordae Tendineae Force}

Among the 48 measurements performed, 2 failed because of sensor attachment problems. CTFs increased 

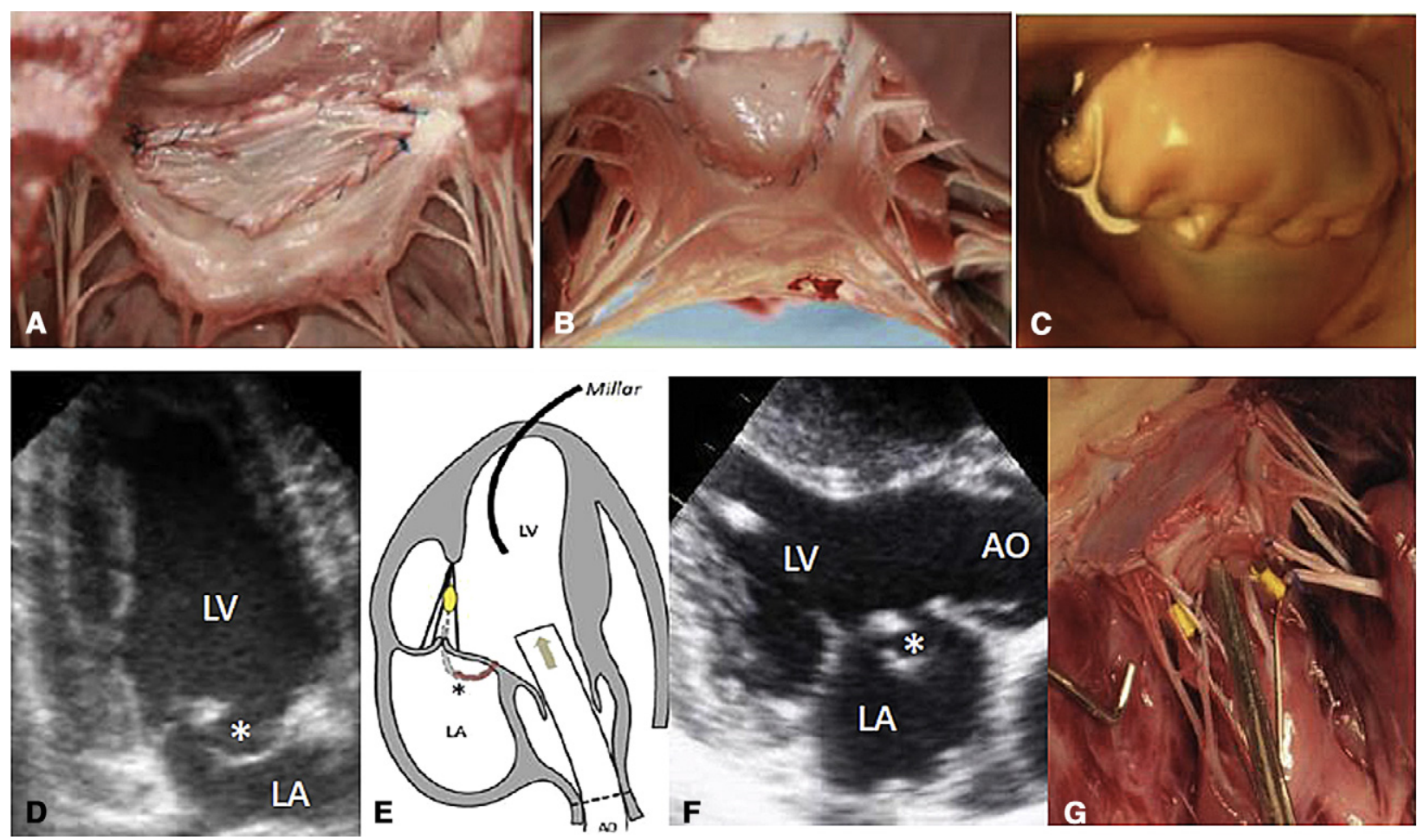

FIGURE 1. Techniques used in ex vivo (A-E) and in vivo (F, G) studies (sheep). After patch insertion, surgical views from the left atrium (A) or ventricle (B) and from the atrium after injection of pressurized water with prolapse (C). Echographic apical 2-chamber views of the closed mitral valve before and after insertion (D) with AML billowing (*). Measurements of LV pressures and chordal tensions (sensor in yellow); changes in pressure originate from aortic injections (arrow) (E). Echographic parasternal long-axis view in systole (F) showing AML billowing (*) after insertion. The sensors (yellow) are sutured onto the strut chordae of the AML $(\mathrm{G}) . A O$, Aortic; $L V$, left ventricle; $L A$, left atrium.

linearly with increasing $\mathrm{LV}$ pressure before and after insertion $(P<.0001)$ (Table 1) with excellent mean correlation coefficients $(0.98 \pm 0.02$ and $0.97 \pm 0.03$ for the posteromedial and anterolateral chordae, respectively). After MVP, CTFs decreased significantly at all pressure levels

TABLE 1. Ex vivo study, chordal tension measurements

\begin{tabular}{ccccc}
\hline Chordae & Before $(\mathbf{N})$ & After $(\mathbf{N})$ & Decrease $(\%)$ & $\boldsymbol{P}$ \\
\hline $50 \mathrm{~mm} \mathrm{Hg}$ & & & & \\
Anterior & $0.35 \pm 0.25$ & $0.21 \pm 0.13$ & $34.7 \pm 27.9$ & .005 \\
Posterior & $0.31 \pm 0.21$ & $0.20 \pm 0.16$ & $31.5 \pm 26.8$ & .014 \\
Total & $0.63 \pm 0.36$ & $0.41 \pm 0.27$ & $39.0 \pm 15.1$ & $<.001$ \\
$75 \mathrm{~mm} \mathrm{Hg}$ & & & & \\
Anterior & $0.61 \pm .36$ & $0.36 \pm 0.22$ & $36.4 \pm 20.5$ & $<.001$ \\
Posterior & $0.50 \pm 0.33$ & $0.34 \pm 0.26$ & $31.2 \pm 28.4$ & .01 \\
Total & $1.1 \pm 0.58$ & $0.69 \pm 0.44$ & $36.5 \pm 16.0$ & $<.001$ \\
100 mm Hg & & & & \\
Anterior & $0.83 \pm 0.41$ & $0.54 \pm 0.31$ & $36.1 \pm 15.4$ & $<.001$ \\
Posterior & $0.69 \pm 0.46$ & $0.49 \pm 0.37$ & $29.3 \pm 23.9$ & .005 \\
Total & $1.52 \pm 0.74$ & $1.02 \pm 0.62$ & $34 \pm 13.0$ & $<.001$ \\
\hline
\end{tabular}

The decrease in tensions (in Newton, N) before and after MVP creation in 11 pig hearts for 3 prespecified $\mathrm{LV}$ pressure levels $(50,75$, and $100 \mathrm{~mm} \mathrm{Hg})$ is demonstrated for the anterior $(\mathrm{A})$ and posterior $(\mathrm{P})$ AML secondary chordae and for the total chordal tension $(\mathrm{A}+\mathrm{P})$. to a similar extent for both chordae (Table 1); total CTFs (sum of anterior and posterior CTFs) decreased to a similar extent.

\section{In Vivo Chordae Tendineae Force}

Among the 8 implanted transducers, 5 transmitted data both before and after MVP, yielding a total of 24 measurements for the different LV pressures. Individual CTFs constantly decreased after MVP $(0.66 \pm 0.24[0.28-0.9] \mathrm{N}$ to $0.41 \pm 0.16[0.15-0.60] \mathrm{N}$, mean $37.9 \%, P<.0001)$. When indexed to concomitant LV pressures, a dramatic $41 \%$ decrease was still noted $(0.68-0.40 \mathrm{~N}, P<.0001)$.

\section{DISCUSSION}

A large animal model of MVP without MR was created by implanting a large oval autologous pericardial patch within the AML. Absence of MR is mandatory to preclude the influence of any regurgitation per se on chordal tension. ${ }^{2}$ The procedure dramatically decreased the tensions exerted on both strut chordae; however, it does not necessarily reflect decreased leaflet wall stress, but might actually reduce stresses on the belly of the patch and conversely increase stresses at the hinge points (the chordae/suture line), as 
previously described in ischemic MR experimentally or after mitral ring annuloplasty. ${ }^{3}$

This preliminary study represents a first step toward the creation of a large animal model of MVP and can be viewed as a description of force redistribution after surgical techniques that use AML patch repair for MR. ${ }^{4}$ The surgeons should be aware of redistribution of leaflet stresses with increased load on the patch area that has been shown to promote fibrosis and calcification.

Finally, because a redistribution of chordal tension may lead to spatially limited biological changes in the mitral valve apparatus, ${ }^{5}$ the long-term influence of such a redistribution of CTF on valve biology necessitates further studies.

The authors thank Marie-Cécile Perier, statistician, INSERM U 970, and Julie Piquet, laboratory technician, Paris
Cardiovascular Research Center, Paris, France, for expert technical contributions.

\section{References}

1. Nielsen SL, Soerensen DD, Libergren P, Yoganathan AP, Nygaard H. Miniature c-shaped transducers for chordae tendineae force measurements. Ann Biomed Eng. 2004;32:1050-7.

2. Stephens EH, Nguyen TC, Itoh A, Ingels NB Jr, Miller DC, Grande-Allen KJ. The effects of mitral regurgitation alone are sufficient for leaflet remodeling. Circula tion. 2008;118(Suppl 14):S243-9.

3. Nielsen SL, Lomholt M, Johansen P, Hansen SB, Andersen NT, Hasenkam JM. Mitral ring annuloplasty relieves tension of the secondary but not primary chordae tendineae in the anterior mitral leaflet. J Thorac Cardiovasc Surg. 2011;141: $732-7$.

4. Romano MA, Patel HJ, Pagani FD, Prager RL, Deeb GM, Bolling SF. Anterior leaflet repair with patch augmentation for mitral regurgitation. Ann Thorac Surg. 2005;79:1500-4

5. Grande-Allen KJ, Griffin BP, Ratliff NB, Cosgrove DM, Vesely I. Glycosaminoglycan profiles of myxomatous mitral leaflets and chordae parallel the severity of mechanical alterations. J Am Coll Cardiol. 2003;42:271-7. 